\title{
FUNCTIONAL OUTCOME 6 MONTHS AFTER SEVERE TRAUMATIC BRAIN INJURY FOLLOWING ADMISSION TO INTENSIVE CARE UNIT: A FOLLOW-UP STUDY IN TWO NEURO-CENTER HOSPITALS
}

\author{
Norain Abdul Rashid ${ }^{1}$, Mohd Basri Mat Nor ${ }^{2}$, Mohamed Saufi Awang ${ }^{3}$ and Salizar \\ Mohamed Ludin ${ }^{1}$ \\ ${ }^{1}$ Critical Care Nursing Department, Kulliyyah of Nursing. ${ }^{2}$ Anaesthesiology \\ Department, Kulliyyah of Medicine. ${ }^{3}$ Surgery Department, Kulliyyah og Medicine.
}

Presenter: Nor'ain Abdul Rashid, norainabdulrashid@gmail.com

Introduction: Traumatic brain injury (TBI) is a major medical and socioeconomic problem. Patients with severe TBI shows physical and functional improvement but remain with cognitive and psycho-social problem throughout recovery. Despite all the issues, the impact of TBI on long-term survivors in Malaysia is unknown. The aim of this study is to measure the functional level of ICU survivors with severe TBI within 6 months post injury.

Materials and method: A cohort study was employed for this study. 33 participants from Hospital Tengku Ampuan Afzan (HTAA) Kuantan, Pahang and Hospital Sultanah Nur Zahirah (HSNZ) Kuala Terengganu with severe TBI were included in this study. The functional assessment of Glasgow Outcome Scale Extended (GOSE) was measured in all samples within in a 6 month period.

Results: The participants mean age was 31.79 with ranged from 16 to 73 years old. The result of this study showed that within 3 months after discharged from the hospital, all the participants still had poor recovery $n=33(100.0 \%)$. Meanwhile, at 6 months after discharge from the hospital, $n=16(48.5 \%)$ participants were scored good recovery. In this case, the SOFA and SAPS II score contributed significantly to the prediction (SOFA score $p=0.045$, SAPS II score $p=0.028$ ) of functional outcome.

Conclusion: The functional outcome of severe TBI improved in six months post injury. The SOFA score and SAPS II score become significant predictors for functional outcome in this study. However, there were some limitations to this study, which are small sample size and short follow-up duration. This study emphasized the importance of SOFA and SAPS II score in predicting functional outcome; thus early care plan should be done if severe TBI have higher SOFA or SAPS II score. 